\title{
Production of Silver Nanoparticle Chains inside Single Wall Carbon Nanotube with a Simple Liquid Phase Adsorption
}

\author{
A. Alimin ${ }^{1,2}$, N. Narsito ${ }^{1}$, Indriana Kartini' ${ }^{1}$, Sri J. Santosa ${ }^{1, *}$ \\ ${ }^{1}$ Department of Chemistry, Universitas Gadjah Mada, Sekip Utara BLS 21 \\ Yogyakarta 55281, Indonesia \\ ${ }^{2}$ Department of Chemistry, Universitas Halu Oleo, Kampus Hijau Bumi Tridharma Anduonohu- \\ Kendari 93232, Indonesia
}

Received: 13 $3^{\text {rd }}$ April 2015; Revised: $4^{\text {th }}$ September 2015; Accepted: $9^{\text {th }}$ September 2015

\begin{abstract}
This article described a successful growing of silver nanoparticle chains (AgNPs) within the internal spaces of single wall carbon nanotube (SWCNT). The use of ethanol in the liquid phase adsorption could produce relatively long silver nanoparticle chains encapsulated in the nanotubes (AgNPsSWCNT). A significant decrease of nitrogen uptake and radial breathing mode (RBM) as well as tangential mode (G band) upshifts of AgNPs-SWCNT specimen suggest that the nanoparticles have been encapsulated in the internal tube spaces of the nanotube. The presence of metallic silvers on the external surface of the carbon nanotube that was observed by scanning electron microscope and examined by X-ray diffraction technique was successfully able to be removed by ultrasonic using $1 \mathrm{M} \mathrm{HNO}_{3}$. The remaining small residue obtained after thermal gravimetric analysis up to $1100 \mathrm{~K}$ supports the suggestion on the presence of silver encapsulated inside SWCNT. (C) 2015 BCREC UNDIP. All rights reserved
\end{abstract}

Keywords: Silver nanoparticles; SG-SWCNT; silver nitrate; ethanol; liquid phase adsorption

How to Cite: Alimin, A., Narsito, N., Kartini, I., Santosa, S.J. (2015). Production of Silver Nanoparticle Chains inside Single Wall Carbon Nanotube with a Simple Liquid Phase Adsorption. Bulletin of Chemical Reaction Engineering \& Catalysis, 10 (3): 266-274. (doi:10.9767/bcrec.10.3.8416.266-274)

Permalink/DOI: http://dx.doi.org/10.9767/bcrec.10.3.8416.266-274

\section{Introduction}

Silver nanoparticles have been actively studied with the relevance to the marked antibacterial effects $[1,2]$ and plasmon resonance $[3,4]$. There are many routes for production of silver particles and nanoparticles [5-7]. In spite of there are not so many studies on the field of silver nanofiber, but some of those describe the UV illumination of $\mathrm{AgBr}$ inside single wall car-

\section{${ }^{*}$ Corresponding Author.}

E-mail address: sjuari@yahoo.com (S. J. Santosa); alkimi_unhalu@yahoo.com (A. Alimin) bon nanotube (SWCNT) giving one-dimensional (1D) silver nanoparticles in the internal tube space [8]. Heating of $\mathrm{AgNO}_{3}$ inside SWCNT at $573 \mathrm{~K}$ leads to formation of silver nanoparticles [9]. Kharlamova and Niu [10] have also heated $\mathrm{AgNO}_{3}$ inside SWCNT at $623 \mathrm{~K}$ for producing silver nanoparticles. Moreover, heating of silver halide under vacuum at $100 \mathrm{~K}$ and $1 \mathrm{~Pa}$ has been reported for growing $1 \mathrm{D}$ silver nanowire inside nanotube channels [11]. Recently, the molten phase technique to produce crystalline AgI nanoparticles inside SWCNT has been used by Ilie et al. [12].

Liquid phase adsorption has been widely used to deposit silver nanoparticles on high 
surface area of carbon [13-15]. The production of silver nanoparticles inside SWCNT with a simple liquid phase adsorption of silver ions must be attempted to develop a smart route to store an active silver in the nanocarbon and to release it with an external stimulation.

Super growth single wall carbon nanotube (SG-SWCNT) which was developed by Hata et al. [16] has bolder wall than SWCNTs prepared by arc and laser ablation method. Then, it can be expected easy formation of silver nanoparticles inside SG-SWCNT due to high diffusivity of solvent having reductive activity. Furthermore, SG-SWCNT has almost no bundle structure and thereby it can be obtained an isolated SWCNT containing silver nanoparticles. Hence, SG-SWCNT is appropriate for pore production of the silver nanoparticle chains inside the tube by the liquid phase adsorption of silver ions with a reductive solvent. Production of the silver nanoparticles encapsulated SWCNT would be promising and opening new avenue in many areas of science and engineering such as catalyst, sensing electrode, electromagnetic radiation protection, etc.

The objective of this study is production of silver nanoparticle chains inside SWCNT using a relatively simple wet process through liquid phase silver ions adsorption in the presence of ethanol.

\section{Materials and Methods}

\subsection{Chemicals}

All chemicals used in this research such as $\mathrm{AgNO}_{3}, \mathrm{HNO}_{3}$ (60 wt.\%) and ethanol (99.5 wt.\%) were purchased from the Wako Chemical Co. SG-SWCNT with high purity of above 99.98 wt.\% supplied by Hata et al. [16] was used in this study.

\subsection{Thermal Oxidation of the SWCNT}

Prior to doping of SWCNT with gadolinium, the SWCNT was oxidized at 723,748 , and 773 $\mathrm{K}$ for $1 \mathrm{~h}$ on air in order to obtain the optimum temperature for opening the end caps. The SWCNT that was oxidized at 723,748 , and 773 $\mathrm{K}$ are denoted as SWCNT-723, SWCNT-748, and SWCNT-773, respectively. The optimum temperature of the oxidized SWCNT sample was determined by nitrogen adsorption isotherm at $77 \mathrm{~K}$ using Quantachrome-AutosorbiQ2-MP apparatus. The optimum temperature of the oxidation was obtained at $748 \mathrm{~K}$. Hence SWCNT-748 was selected for the adsorption experiment.

\subsection{Doping of $\mathrm{AgNO}_{3}$ solution in the SWCNT}

The SWCNT-748 was degassed at room temperature under $0.1 \mathrm{~Pa}$ for $24 \mathrm{~h}$, before doping with $\mathrm{AgNO}_{3}$ solution. The SWCNT of $5 \mathrm{mg}$ was dipped in $\mathrm{AgNO}_{3}$ solution of $25 \mathrm{ppm}$ containing 99.5 wt.\% ethanol and it was then dispersed ultrasonically by a $28 \mathrm{kHz}$ ultrasound apparatus for $48 \mathrm{~h}$ at $298 \mathrm{~K}$. The SWCNT was filtered with a Millipore filter $(0.45 \mu \mathrm{m})$, rinsed with ethanol of $200 \mathrm{~mL}$ and dried at $383 \mathrm{~K}$ for $24 \mathrm{~h}$. The obtained SWCNT sample is denoted as Ag@SWCNT. Silver (Ag) particles formed on the surface of SWCNT was observed by scanning electron microscopic (SEM-JEOL-JSM6335FS) method. The X-ray Diffraction (XRD) technique using monochromatic incident X-ray beam of $\operatorname{MoK}_{a}\left(\lambda_{0}=0.7107 \AA\right.$, RIGAKU 2300 $\mathrm{SF} / \mathrm{RDF}$ with voltage and current of $50 \mathrm{kV}$ and $30 \mu \mathrm{A}$, respectively) was used to confirm the existence of $\mathrm{Ag}$ crystals formed on the surface of the SWCNT.

\subsection{Removal of Silver Particles Formed on the external Surface of SWCNT}

Ag@SWCNT sample was dispersed ultrasonically in $1 \mathrm{M} \mathrm{HNO}_{3}$ for $4 \mathrm{~h}$ at $298 \mathrm{~K}$. The SWCNT sample was filtered and washed with distilled water up to $\mathrm{pH}=7$ and rinsed then with ethanol. The sample was dried in vacuum at $383 \mathrm{~K}$ for $24 \mathrm{~h}$. The obtained SWCNT sample is denoted as AgNPs-SWCNT. This sample was then characterized by nitrogen adsorption isotherm, SEM, transmission electron microscopic (TEM-JEOL-JEM-2100), XRD, and Raman Spectroscopic (RAMAN Renishaw in via Raman microscope equipped with red laser energy of $1.58 \mathrm{eV})$ techniques. The residual metallic silver contained in the sample was analyzed by thermal gravimetric (RIGAKU Thermo plus TG 8120) method under $\mathrm{O}_{2}-\mathrm{N}_{2}$ atmosphere with gas flow and heating rate were $300 \mathrm{ml} . \mathrm{min}^{-1}$ and $3 \mathrm{~K} \cdot \mathrm{min}^{-1}$, respectively.

\section{Results and Discussion}

\subsection{Opening End Caps of the Tube of the SWCNT}

In this study, pore structure of SWCNT was evaluated by nitrogen adsorption isotherms at $77 \mathrm{~K}$. The nitrogen adsorption isotherms of the SWCNT oxidized at different temperatures are shown in Figure 1(a) and (b). It is clearly seen that after oxidation, the $\mathrm{N}_{2}$ uptake increases significantly. The increase could be caused by decapping of the closed-end cap of the tubes. In particular, an explicit increase in the $\mathrm{N}_{2}$ ad- 
sorption below $P / P_{o}=10^{-3}$ indicates the increase of the internal tube volume having a deep interaction potential.

As BET evaluation of the surface area of SWCNT does not lead to the correct surface area [17], the surface area from subtracting pore effect (SPE) was used for discussion here [18]. Even the pristine SWCNT has the high surface area of $1171 \mathrm{~m}^{2} \cdot \mathrm{g}^{-1}$ (Table 1), comparable to the theoretical value of the closed-end caps SWCNT of $1315 \mathrm{~m}^{2} \cdot \mathrm{g}^{-1}$ [19] indicating that the SWCNTs do not form the bundle structure. The maximum surface area of $1620 \mathrm{~m}^{2} \cdot \mathrm{g}^{-1}$ (Table 1) is obtained by oxidation at $748 \mathrm{~K}$, although it is much smaller than the theoretical value of the opened-end caps SWCNT of 2630 $\mathrm{m}^{2} \cdot \mathrm{g}^{-1}[19]$. As SG-SWCNT is defective and the defective parts are reactive, even the oxidation at $773 \mathrm{~K}$, oxidizes markedly to destroy partially the frame structure, decreasing the surface

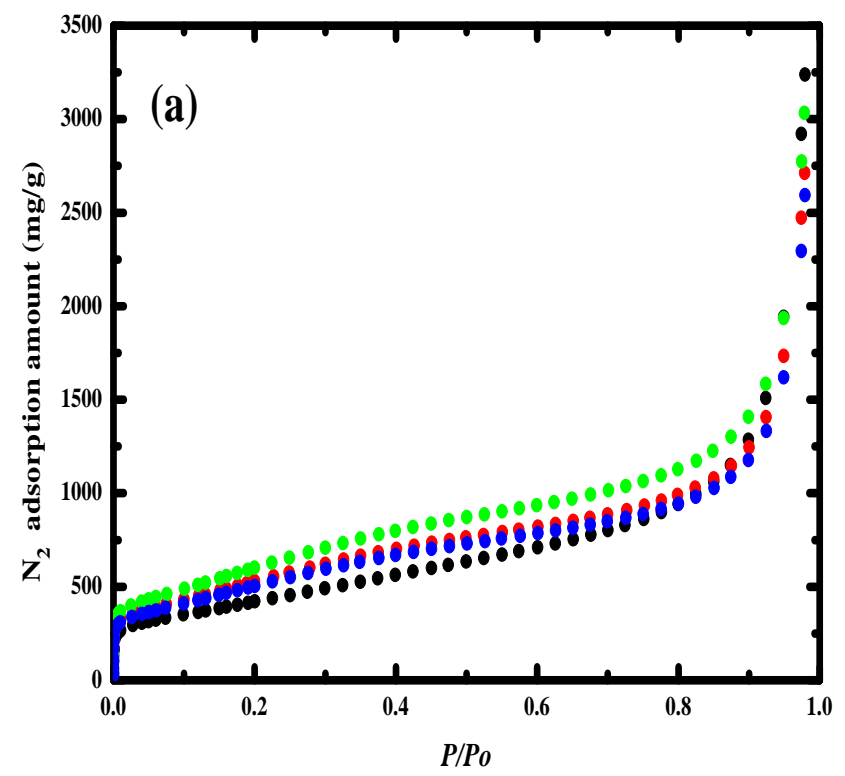

area. The SWCNT-748 is the most fit for growth of silver nanoparticles inside the SWCNT. Only SWCNT-748 was used for doping silver nanoparticles with liquid phase adsorption method. The expression of SWCNT will be used instead of SWCNT-748 in the following.

\subsection{Encapsulation of Silver (Ag) into SWCNT}

Nitrogen adsorption isotherms of AgNPsSWCNT, Ag@SWCNT and non-doped SWCNT are shown in Figure 2. Silver doping treatment remarkably causes the decrease of the adsorbed nitrogen amount by about $65 \%$ in the entire pressure range, indicating that $\mathrm{Ag}$ is encapsulated in the internal tube spaces of SWCNT. A marked decrease in the nitrogen adsorption uptake at low pressure also proves the presence of

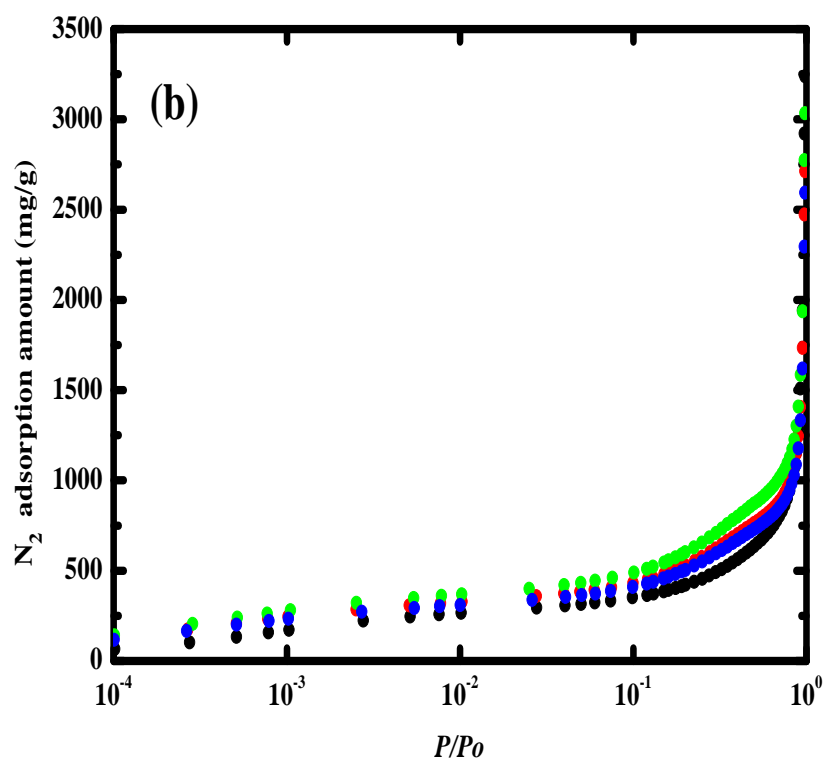

Figure 1. Linear (a) and logarithmic (b) plots of nitrogen adsorption isotherms at $77 \mathrm{~K}$ of the pristine SWCNT (black closed circle), SWCNT-723 (red closed circle), SWCNT-748 (green closed circle) and SWCNT-773 (blue closed circle).

Table 1. Pore structure parameters of SWCNT oxidized at different temperatures

\begin{tabular}{ccc}
\hline Samples & $\begin{array}{c}\text { Surface area }\left(\mathrm{m}^{2} / \mathrm{g}\right) \\
\text { as }\end{array}$ & $\begin{array}{c}\text { Micropore Volume }\left(\mathrm{cm}^{3} / \mathrm{g}\right) \\
\text { as }\end{array}$ \\
\hline SWCNT & 1171 & 0.09 \\
SWCNT-723 & 1434 & 0.41 \\
SWCNT-748 & 1620 & 0.48 \\
SWCNT-773 & 1360 & 0.41 \\
\hline
\end{tabular}

Note: Number following SWCNT denotes oxidation temperature (K) 
encapsulation of $\mathrm{Ag}$ in the internal tube spaces of SWCNT. However, the surface area of Ag@SWCNT is slightly larger than that of AgNPs-SWCNT (Table 2). This phenomenon indicates that the removal of silver particles on the external surface of SWCNT by acid treatment is efficient, since the uptake curve that is near $P / P_{o}=0$ for AgNPs-SWCNT is sharper than that for Ag@SWCNT. The change of micropore volume with encapsulation of silver is almost similar to that of the surface area.

Figure 3 displays radial breathing mode (RBM) of non-doped SWCNT, Ag@SWCNT, and AgNPs-SWCNT. A detail analysis of Raman spectra especially RBM reveals phenomenon of
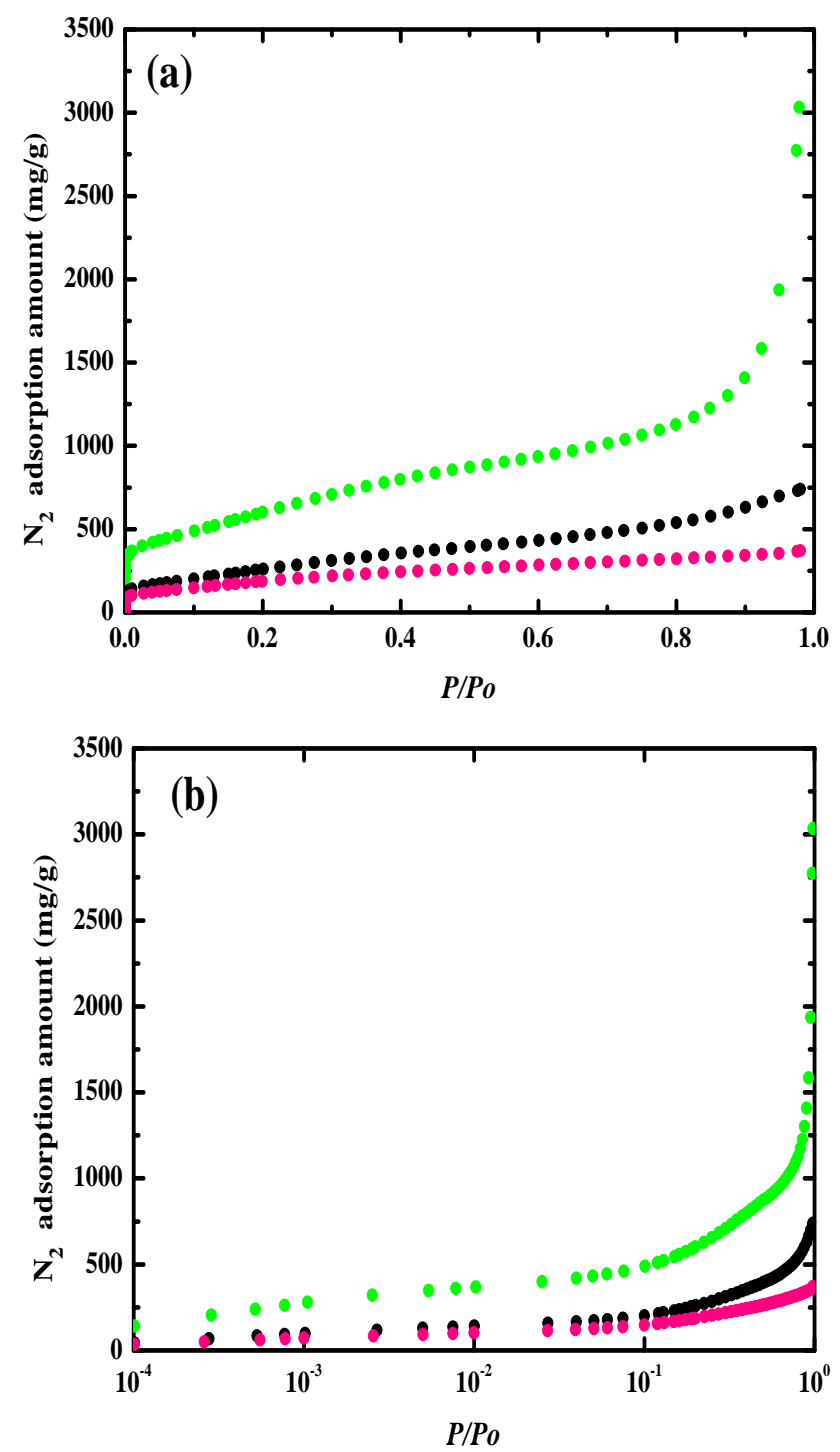

Figure 2. Linear (a) and logarithmic (b) plots of nitrogen adsorption isotherms at $77 \mathrm{~K}$ of non-doped SWCNT (green closed circles), Ag@SWCNT before acid-washing (black closed circles), and AgNPs-SWCNT after acidwashing (pink closed circles) the occurrence of silver encapsulation into SWCNT. It is well-known that the RBM frequency of SWCNT is sensitive to chemical and physical factors as well as the tube diameter of the SWCNT. The relationship between RBM frequency and diameter $(d t)$ tubes of SWCNT is given in Equation (1):

$$
\omega \operatorname{RBM}\left(\mathrm{cm}^{-1}\right)=\mathrm{A} / d t\left(\mathrm{~nm} . \mathrm{cm}^{-1}\right)
$$

where the A is constant of $248 \mathrm{~cm}^{-1}$.

Figure 3 shows that the RBM peaks of the SWCNT exhibit multi-peaks distribution ranging from 146 to $261 \mathrm{~cm}^{-1}$ which correspond to tubes diameter distribution from 0.95 to 1.70

Table 2. The pore structural parameters of $\mathrm{Ag}$ doped SWCNT

\begin{tabular}{lcc}
\hline \multicolumn{1}{c}{ Samples } & $\begin{array}{c}\text { Surface } \\
\text { Area } \\
\left(\mathrm{m}^{2} / \mathrm{g}\right) \\
\mathrm{as}\end{array}$ & $\begin{array}{c}\text { Micropore } \\
\text { Volume } \\
\left(\mathrm{cm}^{3 / g}\right) \\
W_{0}(\mathrm{as})\end{array}$ \\
\hline $\begin{array}{l}\text { Non-doped SWCNT } \\
\text { Ag@SWCNT before }\end{array}$ & 1620 & 0.48 \\
$\begin{array}{l}\text { acid-washing } \\
\text { AgNPs-SWCNT af- } \\
\text { ter acid-washing }\end{array}$ & 419 & 0.16 \\
\hline
\end{tabular}

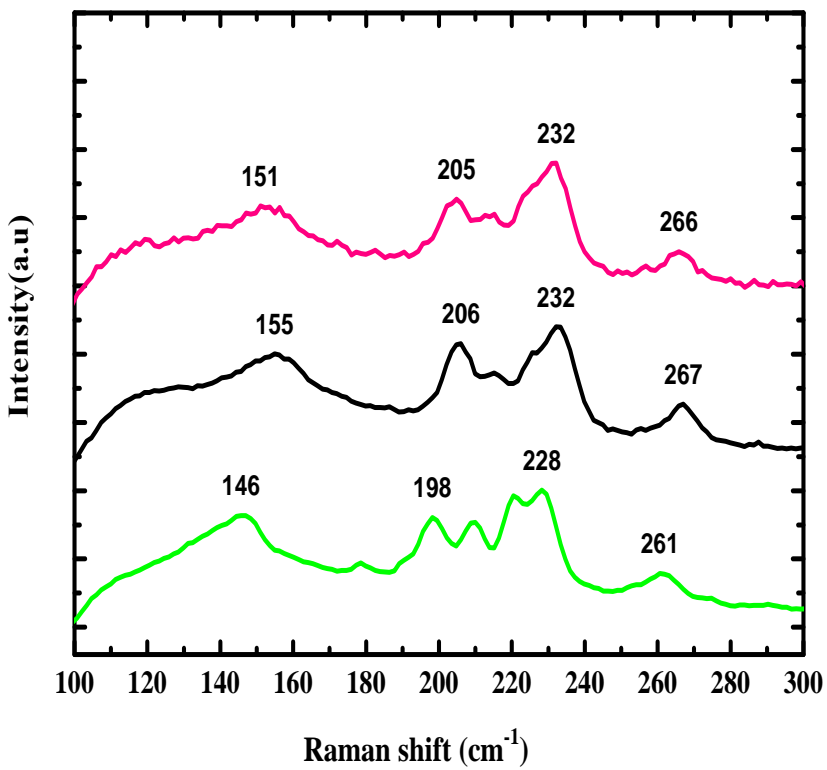

Figure 3. The RBM of non-doped SWCNT (green line), Ag@SWCNT before acid-washing (black line), AgNPs-SWCNT after acid-washing (pink line) using Laser Energy of $1.58 \mathrm{eV}$ 
$\mathrm{nm}$. It suggests that the carbon nanotube is composed of nanotubes with poor homogeneity of diameter size. The RBM regions of Ag@SWCNT and AgNPs-SWCNT significantly shift about $5-9 \mathrm{~cm}^{-1}$ to the higher frequencies. The up shifts of the RBM strongly correspond to smaller tubes diameter as a result of Ag particles encapsulated in the internal tube spaces of the nanotube. The origin of this shifting might be attributed to an increase of $\mathrm{C}-\mathrm{C}$ binding energy due to the charge transfer from SWCNT to metals [11].

The SEM images of SWCNT, Ag@SWCNT (before acid-washing) and AgNPs-SWCNT (after acid-washing) are presented in Figure 4. Many relatively large particles on the external surface of Ag@SWCNT specimen before acidwashing treatment can be observed as shown in Figure 4b. After the treatment, however, those particles could not be observed anymore on the external surface of the nanotube as shown in Figure 4c. In detail, the existence of those particles will be interpreted through XRD patterns of SWCNT as shown in Figure 5.

Figure 5 shows XRD patterns of non-doped SWCNT, Ag@SWCNT and AgNPs-SWCNT. There are broad peaks at around $2 \theta=12^{\circ}$ stemming from the coexistent graphite (002) lattice
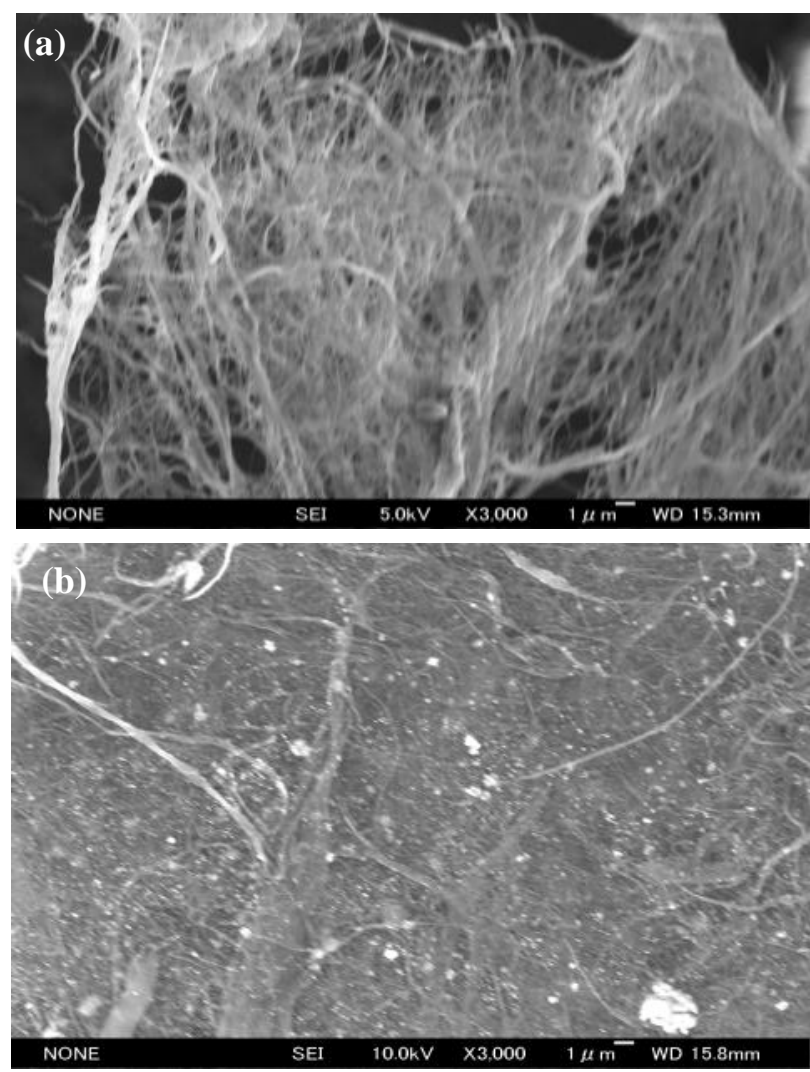

plane in the XRD pattern of SWCNT [21-23]. Broad peaks but slightly weak are also observed at $2 \theta=20^{\circ}$ which are assigned to the reflection from graphite lattice plane of (10) peaks [23]. However, these peaks are not observed in the XRD pattern of AgNPs-SWCNT. A sharp peak at $2 \theta=17^{\circ}$ corresponding to the reflection by the (111) plane of silver metal $[5,24]$ can be observed. In addition, it can be seen that there are two distinct but weak peaks appear at $2 \theta=27^{\circ}$ and $2 \theta=32^{\circ}$ which are assigned to the reflections from the crystallite planes of metallic silvers of (200) and (220) peaks, respectively [5,24], for Ag@SWCNT before acid-washing. It is reasonable that the large particles observed by SEM should be those metallic silvers. Hence,

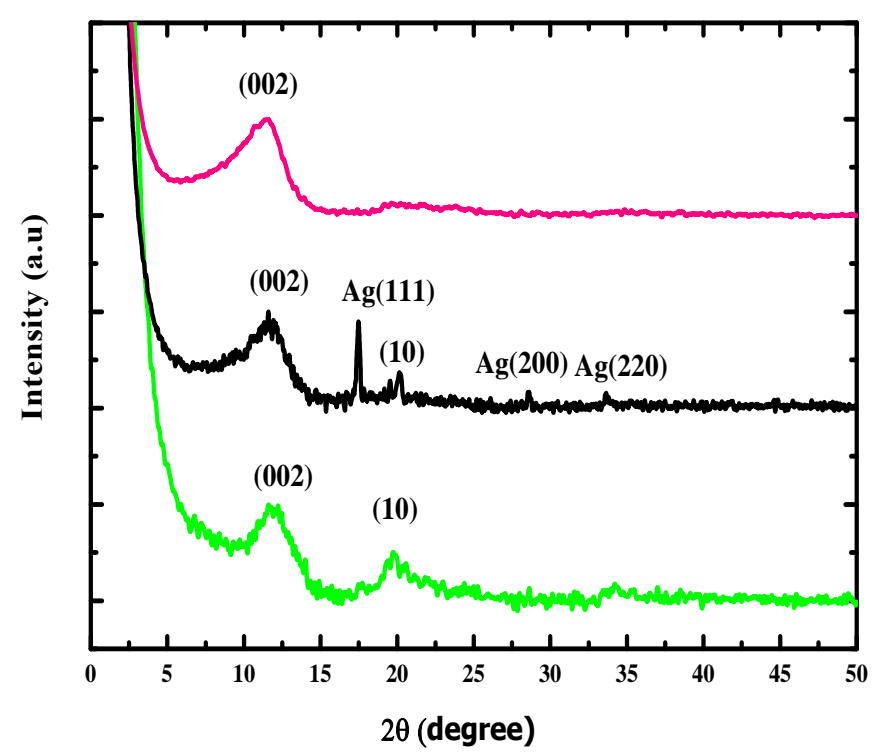

Figure 5. XRD patterns of non-doped SWCNT (green curve), Ag@SWCNT before acidwashing (black curve) and AgNPs-SWCNT after acid-washing (pink curve)

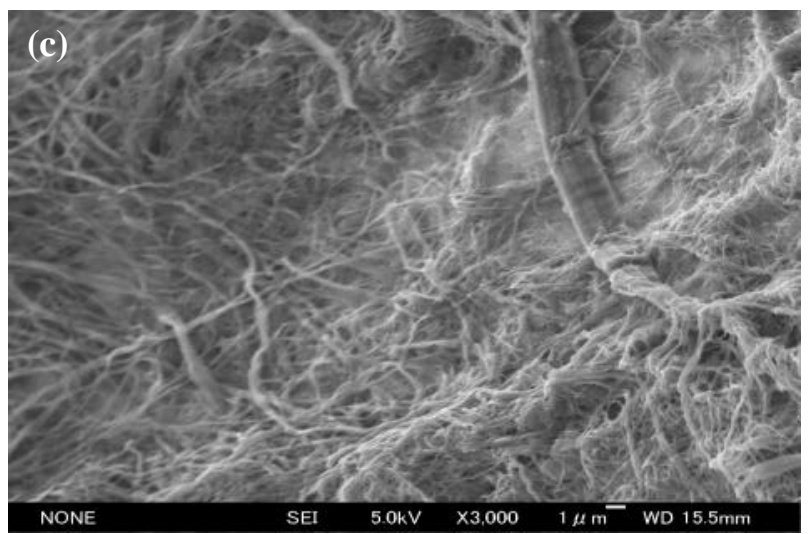

Figure 4. SEM images of non-doped SWCNT (a), Ag@SWCNT before acid-washing (b), and AgNPsSWCNT after acid-washing (c) 
the adsorption method using ethanol can reduce $\mathrm{Ag}^{+}$ions to metallic particles. However, all characteristic peaks of the metallic silvers disappear in the XRD pattern of AgNPs-SWCNT specimen. All large silver particles on the external surface of SWCNT and coexisting with SWCNT should be removed by the removal treatment. The silver nanoparticles inside SWCNT do not give a clear peak as shown in Figure 5. According to the SEM images and XRD patterns, it can be concluded that acidwashing treatment has successfully removed the particles on the external surface of the nanotube.

Regarding silver ions reduction in ethanol, Ayyappan et al. [25] and Grieser et al. [26] suggested that the presence of a primary alcohol $\left(\mathrm{RCH}_{2}-\mathrm{OH} ; \mathrm{R}=\mathrm{H}\right.$ or alkyl group) in the liquid system aided by ultrasonic radiation can produce a radical $\mathrm{RCHOH}^{\cdot}$ and the radical assists the reducing of metal ion to metal, the following reactions can take place [25-27]:

$$
\mathrm{RCH}_{2} \mathrm{OH}+\mathrm{H}^{*} \rightarrow \mathrm{RCHOH}^{*}+\mathrm{H}_{2}
$$

or

$$
\mathrm{RCH}_{2} \mathrm{OH}+\mathrm{OH}^{*} \rightarrow \mathrm{RCHOH}^{*}+\mathrm{H}_{2} \mathrm{O}
$$

where $\mathrm{H}^{\cdot}$ and $\mathrm{OH} \cdot$ is generated from the major reactions occurring when water is sonicated D))))] as given by reaction:

$$
\left.\left.\left.\mathrm{H}_{2} \mathrm{O}\right)\right) \text { )) }\right) \mathrm{H}^{*}+\mathrm{OH}^{*}
$$

Moreover, Ashokkumar and Grieser [27] suggested that reaction taking place on $\mathrm{Ag}^{+}$reduction for producing of AgNPs can be ascribed as follows:

$$
\mathrm{RCHOH}^{*}+\mathrm{Ag}^{+} \rightarrow \mathrm{RCHOH}^{+}+\mathrm{Ag}^{0}
$$

Silver nanoparticles growth can be described by reaction:

$$
\mathrm{nAg}^{\mathrm{o}} \rightarrow(\mathrm{Ag})_{\mathrm{n}}
$$

Another possibility dealing with silver ion reduction, SWCNT might be also able to reduce silver ion to silver particles. SWCNT can be described as single layer of graphene crystal which is rolled up into a cylinder-like [28], and it can be then represented by benzene rings. In addition, since $\mathrm{Ag}^{+}$and SWCNT have standard reduction potentials of $+0.8 \mathrm{~V}$ and $-0.5 \mathrm{~V}$, re- spectively [29-31], then it is proposed a model of redox mechanism as follows. When $\mathrm{Ag}^{+}$interacts with benzene rings of SWCNT, a phi electron in the benzene rings can be donated to $\mathrm{Ag}^{+}$ion as an acceptor agent then cationic SWCNT and $\mathrm{Ag}(0)$ are produced. The pathway of the reduction mechanism can be ascribed as follows:

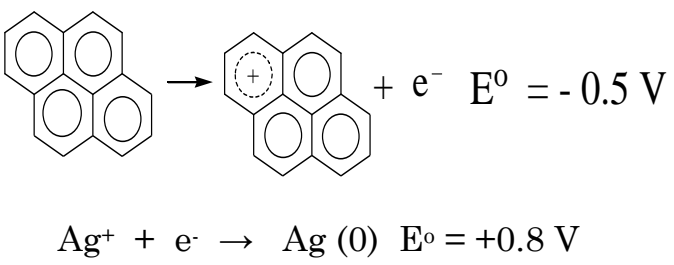

The sum of Equations (7) and (8) obtains the overall reaction as follows:

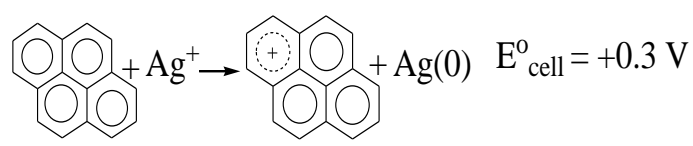

Since reaction cell potential $\left(\mathrm{E}^{\mathrm{o}}\right.$ cell $)$ of $\mathrm{Ag}^{+}$ion reduction is $+0.3 \mathrm{~V}$, redox reaction should take place spontaneously.

Figure 6 exhibits the TEM images of SWCNT before doping and after doping as well as after acid-washing treatment. The SWCNTs do not form the clear bundle structure as observed in other SWCNT. The presence of silver nanoparticles inside SWCNT after doping treatment of silver can be observed as demonstrated in Figures 6(b) and (c), there are also relatively large silver particles (inset in Figure 6b) before washing with $\mathrm{HNO}_{3}$ solution.

Even though the large particles disappeared after the washing, nanoparticles forming relatively long nanowires-like inside SWCNT still could be observed (Figure 6c). The presence of the nanoparticles could also be attributed to the $\mathrm{G}$ band shifting of Raman spectra as shown in Figure 7 indicating that $\mathrm{G}$ band frequencies of Ag@SWCNT and AgNPs-SWCNT specimens dramatically shift to higher frequency up to 9 $\mathrm{cm}^{-1}$ compared with the non-doped SWCNT. The $\mathrm{G}$ band denoted as $\omega G^{+}$is sensitive to charge transfer from dopant additions to SWCNT. The up shift of the $\omega G^{+}$is caused by the fact that silver particles can act as an electron acceptor with respect to SWCNT and the corresponding shift of the Fermi edge takes place. In the other word, SWCNT donates charge to silver particles so that the $\omega G^{+}$of the SWCNT shifted to higher frequency. This phenomenon is in good agreement with work of Eliseev et al. [11].

The TEM observation strongly proves encapsulation of silver nanoparticles inside SWCNT, agreeing with the marked porosity change from 
$\mathrm{N}_{2}$ adsorption and RBM upshifts of Raman Spectra as described before.

Figure 8 exhibits thermal gravimetric analysis (TGA) profiles of the non-doped SWCNT and AgNPs-SWCNT. The sharp weight losses
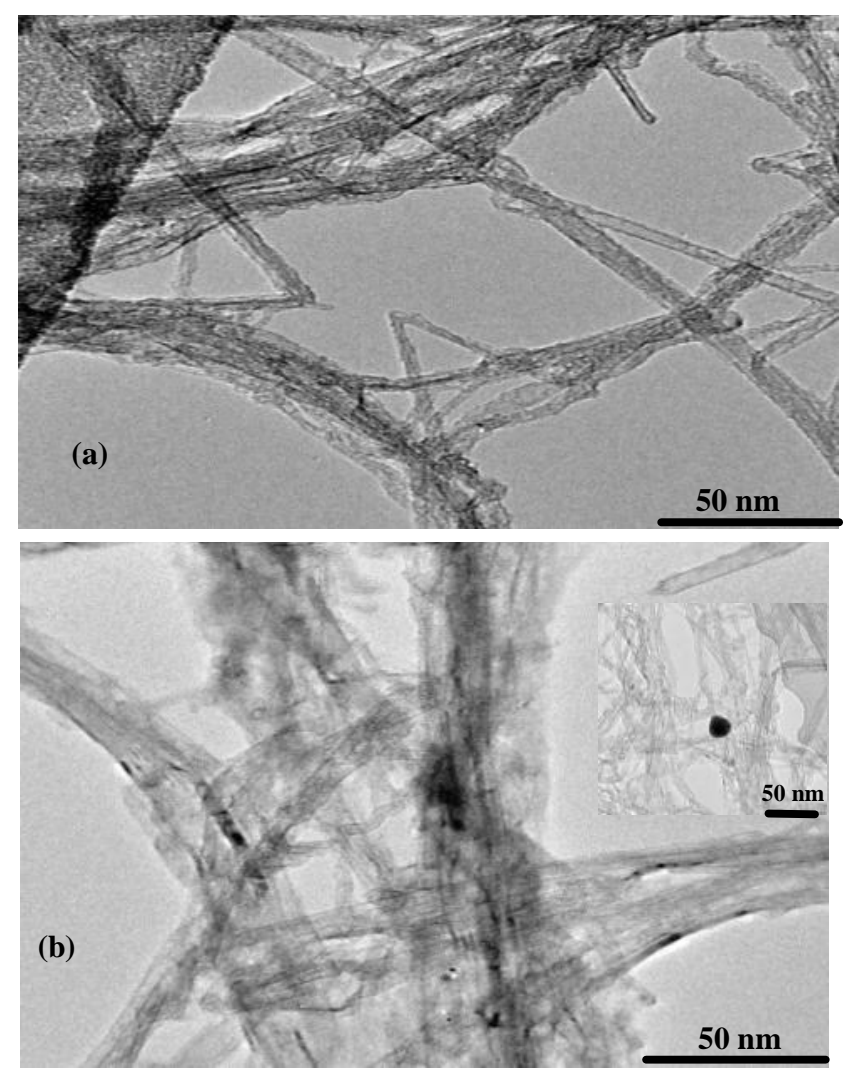

of the non-doped SWCNT and AgNPs-SWCNT which rise at about $750 \mathrm{~K}$ stem from oxidation of carbon materials. The thermal stability of AgNPs-SWCNT is slightly lower than that of the non-doped SWCNT. It might be due to the formation of silver oxides in the AgNPs-SWCNT specimen during oxidation. The weight loss extends to $950 \mathrm{~K}$ leaving a lower residue of $0.42 \mathrm{wt}$ $\%$ for the specimen. However, the weight losses of the non-doped SWCNT could not be detected. This residue should be the silver oxides originating from metallic silver which was encapsulated in the internal tube spaces of nanotube. The lower residue and the decrease of thermal stability of AgNPs-SWCNT specimen support the existence of those nanoparticles inside SWCNT.

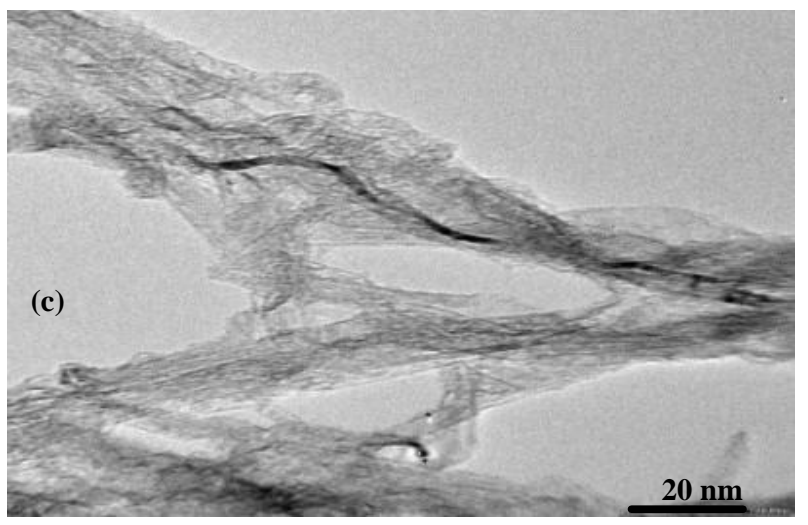

Figure 6. TEM images of non-doped SWCNT (a), Ag@SWCNT before acid-washing (b), and AgNPsSWCNT after acid-washing (c)

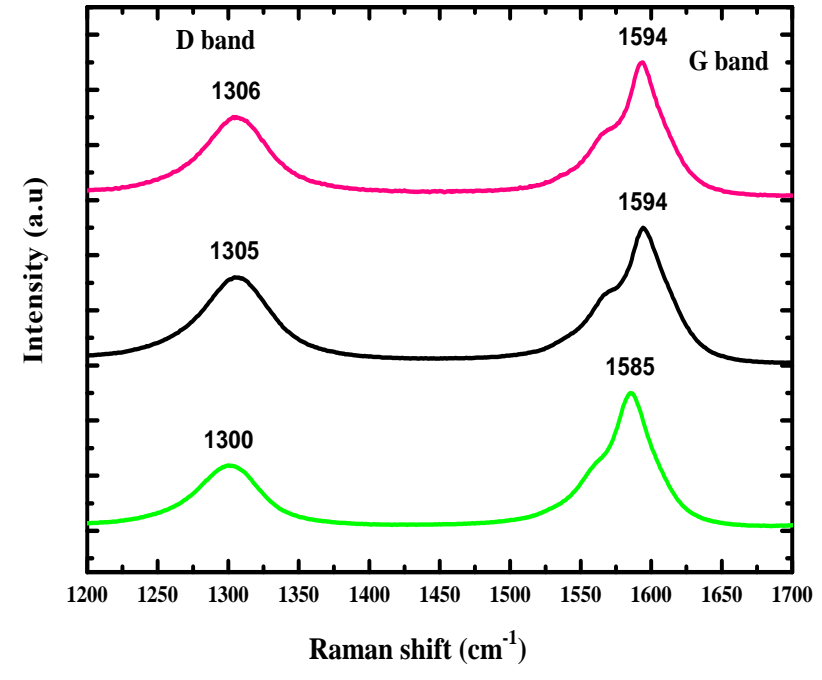

Figure 7. The D and G bands of non-doped SWCNT (green line), Ag@SWCNT before acidwashing (black line), AgNPs-SWCNT after acid-washing (pink line) using Laser Energy of $1.58 \mathrm{eV}$

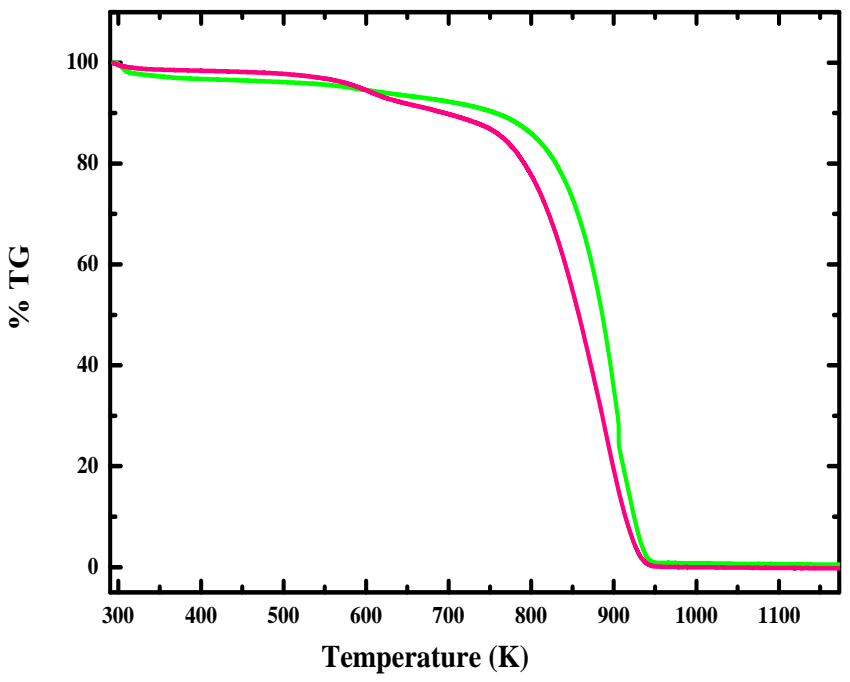

Figure 8. TGA profiles of AgNPs-SWCNT after acid-washing (pink line) and non-doped SWCNT (green line) 


\section{Conclusions}

The application of ethanol as phase adsorption has successfully produced a relatively long silver nanowire-like AgNPs. The acid-washing treatment using mild concentration of $1 \mathrm{M}$ $\mathrm{HNO}_{3}$ has effectively removed silver particles which were not incorporated in the internal tube spaces of the nanotube. It was evidenced that after the acid-washing, the silver nanoparticles encapsulated in the internal tube spaces of SWCNT still could be observed. Production of AgNPs inside SWCNT would be projected to be one of the most promising materials due to distinctive structure and extraordinary properties of SWCNT such as high electronic conductivity, very lightweight, harder than diamond.

\section{Acknowledgments}

The authors thank the Center for Energy and Environmental Science, Shinshu University-Japan for the research project. The authors deeply thank Professor Katsumi Kaneko for giving the great opportunity to study and perform research under his supervision at the Center for Energy and Environmental Science, Shinshu University-Japan.The authors thank Professor Morinobu Endo of Center for Energy and Environmental Science, Shinshu University-Japan for TEM, SEM and TGA equipment. The authors thank Professor K. Hata for supplying the SG-SWCNT. The authors thank Associate Professor Toshihiko Fujimori for his advices and intensive discussion of Raman spectroscopy and XRD theory. The authors thank Dr. Daiki Minami for his great support of TEM observation. The authors thank Dr. Ryusuke Futamura for his guidance of the XRD experiment. The authors thank Dr Fitri Khoerunnisa for her kindly experimental guidance and intensive discussion. The authors thank Dr. H. Sakamoto, Dr. Suwen Wang, Dr. Fernando Vallejos Burgos, Radovan Kukobat and $\mathrm{Li}$ Xiaolin for their supports and advices.

\section{References}

[1] Niu, A., Han, Y.,Wu, J., Yu, N., Xu, Q. (2010). Synthesis of One-Dimensional Carbon Nanomaterials Wrapped by Silver Nanoparticles and Their Antibacterial Behavior. Journal of Physical Chemistry. C, 114: 12728-12735.

[2] You, C., Han, C., Wang, X., Zheng, Y., Li, Q., Hu, X., Sun, H. (2012). The Progress of Silver Nanoparticles in the Antibacterial Mechanism, Clinical Application and Cytotoxicity, Molecular Biology Report, 39: 9193-9201.
[3] Gong, H. M., Zhou, Z.K., Xiao, S., Su, X.R., Wang, Q.Q. (2008). Strong Near-infrared Avalanche Photoluminescence from Ag Nanowire Arrays, Plasmonics, 3: 59-64.

[4] Margueritat, J., Gonzalo, J., Afonso, C.N., Mlayah, A., Murray, D.B., Saviot, L. (2006). Surface Plasmons and Vibrations of SelfAssembled Silver Nanocolumns, Nano Letter, 6 (9): 2037-2042.

[5] Choi, S.K., Chun, K.Y., Lee, S.B. (2009). Selective Decoration of Silver Nanoparticles on the Defect Sites of Single-Walled Carbon Nanotubes, Diamond \& Related Materials, 18: 637641.

[6] Fu, H., Yang, X., Yu, A., Jiang, X. (2013). Rapid Synthesis and Growth of Silver Nanoparticles Induced by Vanadium Trioxide Particles, Particuology. 11: 428-440.

[7] Lee, J.H., Lee, P., Lee, D., Lee, S.S., Ko, S.H. (2012). Large-Scale Synthesis and Characterization of Very Long Silver Nanoparticles via Successive Multistep Growth, Crystal Growth Design, 12: 5598-5605.

[8] Kobayashi, K., Suenaga, K., Saito, T., Shinohara, H., Iijima, S. (2010). Photoreactivity Preservation of $\mathrm{AgBr}$ Nanoparticles in Confined Nanospaces, Advanced Materials, 22: 3156-3160.

[9] Borowiak-Palen, E., Ruemmeli, M.H., Gemming, T., Pichler, T., Kalenczuk, R.J., Silva, S.R.P. (2006). Silver Filled Single-Wall Carbon Nanotubes - Synthesis, Structural and Electronic Properties, Nanotechnology, 17: 24152419.

[10] Kharlamova, M.V., Niu, J.J. (2012). Comparison of Metallic Silver and Copper Doping Effects on Single-Walled Carbon Nanotubes, Applied Physics. A, 109: 25-29.

[11] Eliseev, A.A., Yashina, L.V., Brzhezinskaya, M.M., Chernysheva, M.V., Kharlamova, M.V., Verbitsky, N.I., Lukashin, A.V., Kiselev, N.A., Kumskov, A.S., Zakalyuhin, R.M., Hutchison, J.L., Freitag, B., Vinogradov, A.S. (2010). Structure and Electronic Properties of AgX (X $=\mathrm{Cl}, \mathrm{Br}, \mathrm{I})$-Intercalated Single-Walled Carbon Nanotubes, Carbon, 48: 2708-2721.

[12] Ilie, A., Crampin, S., Karlsson, L., Wilson, M. (2012). Repair and Stabilization in Confined Nanoscale Systems-Inorganic Nanoparticles within Single-Walled Carbon Nanotubes, Nano Research, 5 (12): 833-844.

[13] Fortunati, E., D’Angelo, F., Martino, S., Orlacchio, A., Kenny, J.M., Armentano, I. (2011). Carbon Nanotubes and Silver Nanoparticles for Multifunctional Conductive Biopolymer Composites, Carbon, 49: 2370-2379. 
[14] Sahoo, S., Husale, S., Karna, S., Nayak, S.K., Ajayan, P.M. (2011). Controlled Assembly of $\mathrm{Ag}$ Nanoparticles and Carbon Nanotube Hybrid Structures for Biosensing, Journal of the American Chemical Society. 133: 4005-4009.

[15] Tokuno, T., Nogi, M., Jiu, J., Suganuma, K. (2012). Hybrid Transparent Electrodes of Silver Nanoparticles and Carbon Nanotubes: A Low-Temperature Solution Process, Nanoscale Research Letters, 7(281): 1-7

[16] Hata, K., Futaba, D.N., Mizuno, K., Namai, T., Yumura, M., Iijima, S. (2004). WaterAssisted Highly Efficient Synthesis of Impurity-Free Single-Walled Carbon Nanotubes Science, 306: 1362-1364

[17] Ohba, T., Kaneko, K. (2002). Internal Surface Area Evaluation of Carbon Nanotube with GCMC Simulation-Assisted $\mathrm{N}_{2}$ Adsorption, Journal of Physical Chemistry. B, 106: 71717176.

[18] Setoyama, N., Suzuki, T., Kaneko, K. (1998). Simulation Study on the Relationship Between A High Resolution As-Plot and the Pore Size Distribution for Activated Carbon, Carbon, 36: 1459-1467.

[19] Kaneko, K., Itoh, T., Fujimori, T. (2012). Collective Interactions of Molecules with an Interfacial Solid, Chemical Letters, 41: 466-475.

[20] Jorio, A., Pimenta, M.A., Souza Filho, A.G., Saito, R., Dresselhaus, G., Dresselhaus, M.S. (2003). Characterizing Carbon Nanotube Samples with Resonance Raman Scattering, New Journal of Physics, 5: 139.1-139.17.

[21] Maniwa, Y., Kumazawa, Y., Saito, Y., Tou, H., Kataura, H., Ishii, H., Suzuki, S., Achiba, Y., Fujiwara, A., Suematsu, H. (1999). Anomaly of X-ray Diffraction Profile in Single-Wall Carbon Nanotubes, Japanese Journal of Applied Physics, 38: 668-670.

[22] Miyata, Y., Yanagi, K., Maniwa, Y., Tanaka, T., Kataura, H. (2008). Diameter Analysis of Rebundled Single-Wall Carbon Nanotubes Using X-ray Diffraction: Verification of Chirality Assignment Based on Optical Spectra, Journal Physical Chemistry C, 112: 15997 -16001 .
[23] Khoerunnisa, F., Fujimori, T., Itoh, T., Urita, K., Hayashi, T., Kanoh, H., Ohba, T., Hong, S.Y., Choi, Y.C., Santosa, S.J., Endo, M., Kaneko, K. (2012). Enhanced $\mathrm{CO}_{2}$ Adsorptivity of Partially Charged Single Walled Carbon Nanotubes by Methylene Blue Encapsulation, Journal of Physical Chemistry C, 116: 11216-11222.

[24] Sun, Y., Xia, Y. (2002). Shape-Controlled Synthesis of Gold and Silver Nanoparticles, Science, 298: 2176-2179.

[25] Ayyappan, S., Gopalan, R.S., Subbanna, G.N., Rao, C.N.R. (1997). Nanoparticles of Ag, Au, $\mathrm{Pd}$, and $\mathrm{Cu}$ Produced by Alcohol Reduction of the Salts, Journal of Materials Research, 12(2): 398-401.

[26] Grieser, F and Hobson, R., Sostaric, J., Mulvaney, P. (1996). Sonochemical Reduction Processes in Aqueous Colloidal Systems, Ultrasonics, 34: 547-550.

[27] Ashokkumar, M., Grieser, F. (2002). Sonochemical Preparation of Colloids, Encyclopedia of Surface and Colloid Science, Marcel Dekker, Inc.

[28] Dresselhaus, M.S., Dresselhaus, G., Eklund, P.C. (1996). Science of Fullerenes and Carbon Nanotubes, Academic Press.

[29] Bard, A.J., Faulkner, L.R. $2^{\text {nd }}$ ed. (2001). Electrochemical Methods-Fundamental and Application. John Wiley \& Sons.Inc.

[30] Suzuki, S., Bower, C., Watanabe, Y., Zhou, O. (2000). Work Functions and Valence Band States of Pristine and Cs-Intercalated Single Walled Carbon Nanotube Bundles, Applied Physic Letters, 76(26): 4007-4009.

[31] Choi, H.C., Shim, M., Bangsaruntip, S., Dai, H. (2002). Spontaneous Reduction of Metal Ions on the Sidewalls of Carbon Nanotubes, Journal of American Chemical Society, 124: 9058-9059. 